\title{
Testing the effect of soak time on catch damage in a coastal gillnetter and the consequences on processed fish quality
}

Savina, Esther; Karlsen, Junita Diana; Frandsen, Rikke; Krag, Ludvig Ahm; Kristensen, Kasper; Madsen, Niels

Published in:

Link to article, DOI:

10.1016/j.foodcont.2016.05.044

Publication date:

2016

Document Version

Peer reviewed version

Link back to DTU Orbit

Citation (APA):

Savina, E., Karlsen, J. D., Frandsen, R., Krag, L. A., Kristensen, K., \& Madsen, N. (2016). Testing the effect of soak time on catch damage in a coastal gillnetter and the consequences on processed fish quality. Food

Control, 70, 310-317. https://doi.org/10.1016/j.foodcont.2016.05.044

\section{General rights}

Copyright and moral rights for the publications made accessible in the public portal are retained by the authors and/or other copyright owners and it is a condition of accessing publications that users recognise and abide by the legal requirements associated with these rights.

- Users may download and print one copy of any publication from the public portal for the purpose of private study or research.

- You may not further distribute the material or use it for any profit-making activity or commercial gain

- You may freely distribute the URL identifying the publication in the public portal 


\section{Testing the effect of soak time on catch damage in a coastal gillnetter and the consequences on processed fish quality}

Esther Savina ${ }^{\mathrm{a}}$, Junita Diana Karlsen ${ }^{\mathrm{a}}$, Rikke Petri Frandsen, Ludvig Ahm Krag ${ }^{\mathrm{a}}$, Kasper

Kristensen ${ }^{\mathrm{b}}$, Niels Madsen ${ }^{\mathrm{a}}$

a Technical University of Denmark, National Institute of Aquatic Resources, North Sea Science Park, PO Box 101, DK-9850, Hirtshals, Denmark

b Technical University of Denmark, National Institute of Aquatic Resources, Charlottenlund Slot- Jægersborg Allé 1, DK-2920, Charlottenlund, Denmark

\section{CORRESPONDING AUTHOR}

Esther Savina, esav@aqua.dtu.dk, +45 35883200

Technical University of Denmark, National Institute of Aquatic Resources, North Sea Science Park, PO Box 101, DK-9850, Hirtshals, Denmark

\section{ABSTRACT}

This study aims at testing how to improve catch quality aboard a coastal gillnetter by looking at an easily controllable parameter known to have an effect on the degree of fish damage, soak time, and investigating if the registered damages on whole fish have an effect on processed products such as fillets. Plaice (Pleuronectes platessa) was captured with commercial gillnets soaked for 12 and 24 hours. Damages were assessed using semiquantitative indices of individual fish condition gathered in a Catch-damage-index for onboard fish and a Processed fish-damage-index for whole, skinned and filleted plaice processed at a land-based factory. Cumulative link mixed modelling allowed the estimation of the size of effects. Damage in fish was significantly more likely for longer soak times but effects were comparable to those of fish length and between-sets, making a change in soak time not so substantial for improving plaice quality in coastal gillnetting. Damage in fish was significantly more likely for whole than filleted fish, but there was substantial heterogeneity among fish. Severe damage in whole fish may not matter in filleted fish whereas some damage may only be visible at the fillet level.

Keywords: Catch-damage-index, cumulative link mixed model, gillnet, plaice, product quality, soak time 


\section{Introduction}

The gillnet fleet is of importance in Denmark and is gaining interest as an alternative practice towards improved environmental sustainability with regard to energy use and ecosystem effects (Andersen, Ulrich, Eigaard, \& Christensen, 2012; Suuronen et al., 2012).

The coastal vessels provide the opportunity of daily fresh fish supply, but maintaining profitable is challenging, and calls for solutions to help improve catch production. Raw material is increasingly identified as a key factor in fish quality, and catch damages may result in reduced price or discarding (Esaiassen, Akse, \& Joensen, 2013; Lawler, 2003; Margeirsson, Jonsson, Arason, \& Thorkelsson, 2007; Santos, Gaspar, Monteiro, \& Vasconcelos, 2002). In the gillnet fisheries, more fish are discarded due to poor quality than being below the legal minimum landing size (Batista, Teixeira, \& Cabral, 2009; Borges et al., 2001; Gonçalves et al., 2008; Morandeau et al., 2014). Challenges in gillnets are that fish can die in the gear when the net is soaked, the netting can cause marks on the fish skin, and there is an increased risk of injuries due to predation or scavenging of fish in the gear (Auclair, 1984; Perez \& Wahrlich, 2005; Petrakis, Cheilari, \& Cambiè, 2010; Santos et al., 2002; Suuronen et al., 2012). Improvement in catch quality is important for the coastal gillnet fisheries as it may limit wastage of raw materials, maximize production for the industry and benefit to consumers.

Among the parameters that matter on the quality value of the raw material such as environmental variations or handling and storage methods, capture procedure, especially soak time, is a controllable parameter (Esaiassen et al., 2013; Olsen et al., 2014; Özogul \& Özogul, 2004; Özyurt et al., 2007). It might be an advantage for the fishermen to soak for long time periods to maximise catch per unit effort, but previous experiments have shown that the proportion of dead fish and degree of damage increase with the soak time (Acosta, 1994; Hickford \& Schiel, 1996; Hopper et al., 2003; Petrakis et al., 2010; Santos et al., 2002; Suuronen et al., 2012). Natural variations such as fish length are also known to influence quality (Esaiassen et al., 2013). As there might be no effect of the registered damage on whole fish in processed products such as fillets, severity of catch damage in whole fish has to be analysed against the quality of processed products (Esaiassen et al., 2013).

In the coastal fishery, fish is usually landed less than one day after capture and freshness, i.e., age of the raw material, which is usually perceived as the most important attribute of the quality of fish, is not appropriate (Denton, 2003; Esaiassen et al., 2013; Martinsdóttir, Luten, 
Schelvis-Smit, \& Hyldig, 2003). Instead, previous studies have used semi-quantitative indices of individual fish condition grouped in an index to evaluate whole or processed fish damage in fishing gears (Depestele, Desender, Benoît, \& Polet, 2014; Digre, Hansen, \& Erikson, 2010; Digre, Tveit, Solvang-Garten, Eilertsen, \& Aursand, 2016; Karlsen, Krag, Albertsen, \& Frandsen, 2015; Olsen, Tobiassen, Akse, Evensen, \& Midling, 2013; Rotabakk, Skipnes, Akse, \& Birkeland, 2011). Most studies used hypothesis testing which does not allow for the estimation of the size of effects, unlike model-based methods such as cumulative link mixed modelling which is appropriate for ordinal multi-category responses. It also tolerates random effects which are relevant here to account for within-haul (or set) correlations as well as to tackle scoring subjectivity, i.e., there may be differences in the assessment when all fish in a set are in similar condition or when they show a broader range of damage severities (Benoît, Hurlbut, \& Chassé, 2010).

This study aimed at assessing (1) the effect of soak time in comparison with an uncontrollable natural variation, fish length, and set effect on catch damage onboard a commercial gillnetter and (2) the change in quality between whole fish, and skinned and filleted products at a land-based processing factory. Plaice (Pleuronectes platessa), one of the main target species in the Danish coastal gillnet fisheries, was taken as a case study.

\section{Materials and methods}

\subsection{Experimental design and sea trials}

Trials were conducted on the commercial gillnetter HG5 Skovsmose $(11.99 \mathrm{~m}, 171 \mathrm{~kW})$ in the Skagerrak coastal waters for eight consecutive days in September 2014. Commercial plaice gillnets with $136 \mathrm{~mm}$ nominal stretched mesh size and $0.30 \mathrm{~mm}$ twine were used in all sets. Each net was $2 \mathrm{~m}$ (stretched) high, $82 \mathrm{~m}$ long and slackly hung with a hanging ratio of 25\%. Three individual nets were attached together by connecting the sink and float lines at the start and end of each net ( $2 \mathrm{~m}$ apart of one another) to form a fleet, i.e., a ganged sequence. In total, nine fleets were constituted. The soak times 12 and 24 hours (h) covered the usual range of commercial practices in Danish coastal waters. Every day, three fleets were soaked for $24 \mathrm{~h}$. Simultaneously, three fleets were soaked for $12 \mathrm{~h}$ during the day and three others during the night to account for a possible day-night effect. The nets were located over a single known habitat type, sandy bottom, at the same depth. Fleets were randomly positioned to avoid any spatial effect, and spaced by a minimum distance of $111 \mathrm{~m}$ in latitude and $60 \mathrm{~m}$ in longitude to 
prevent competition between them. Fleets were set with the current, parallel to the coast, and anchored at both ends using $6 \mathrm{~m}$ bridle lines and $4 \mathrm{~kg}$ anchors following commercial practices. Fleets were hauled aboard the vessel using a hydraulically-powered net hauler with top roller.

\subsection{Handling of the catch}

Two professional fishermen disentangled the catch from the netting on a sorting table during hauling, and put it in open mesh baskets making sure not to overfill them. The same scientist sorted all captured fish from the baskets, measured and assessed whole plaice for catch damage on deck immediately after hauling in a dedicated work station protected from wind to prevent dehydration of fish. Plaice below the legal minimum landing size of $27 \mathrm{~cm}$ (EU, 2013), dead fish or those below the freshness category B according to the European Union scheme (EU, 1996) and considered unfit for consumption were not landed according to commercial practices. Retained fish were handled following standard commercial practices. Fish were washed to remove debris in the open mesh baskets with an adequate supply of clean seawater from a hose. The two professional fishermen gutted the fish, i.e., the intestinal tract and internal organs were removed, by hand with a knife. Gutted fish were cleaned in a washing tank for a minimum of five minutes with seawater to remove blood and viscera from the belly cavity. The scientist checked for the quality of bleeding by gutting. Fish were discharged down a chute to the cooling room below deck, where the individuals from the three soak times were stored separately in standard plastic boxes in shallow layers surrounded by fine melting ice following standard commercial practices for later assessment at a fish processing factory.

\subsection{Quality assessment}

All captured plaice were assessed for catch damage onboard the vessel (Fig. 1) using a Catch-damage-index (CDi) initially elaborated for gadoids by Esaiassen et al. (2013) and adapted for flatfish with the following minor adaptations. The CDi scheme lists damages caused by fishing gear and handling onboard together with scores relative to the severity of the damage and its influence on the quality of the raw material (Table 1). Damages were scored according to their position on the fish and were considered moderate when in fin or tail part and severe when in body part. A fish was considered dead if it did not show gill movement and was unresponsive to touch immediately after hauling the catch onboard. As all 
the individuals were faultlessly bled by gutting and there was no use of gaffs, the two attributes 'poorly bled' and 'gaffing damage' were not included in the assessment scheme. The scores for each attribute in the CDi scheme ranged from 0 for flawless to 2 for most severe (Table 1, see Fig. 2 for examples of ratings). The CDi was then calculated for each individual by summing the scores for all attributes. The CDi scale ranged from 0 for flawless to 12 for most severe.

To limit the variation in factors that could have an influence on the assessment of landed fish at the processing factory, only sets for which similar storage conditions could be guaranteed were included in the analysis. The assessment was exclusively run for the $12 \mathrm{~h}$ soaks at night and 24h soaks, and only for five of the seven days of data collection. Onboard storage of the fish assessed at the factory lasted no more than 4h. After landing, eight fish from each of the two soak time categories (12h at night and $24 \mathrm{~h})$ were randomly picked and labelled (Fig. 1). These fish were kept until the next day in a cooling room at $2^{\circ} \mathrm{C}$ in two standard commercial plastic boxes. The boxes were kept one on top of the other with an empty plastic box on top to prevent differential drying of the fish. On the day following hauling of the net, fish were brought to the fish factory, and assessed for quality by the same quality representative from the factory using a Processed fish-damage-index developed for the purpose of this experiment. This scheme lists the attributes looked at by exporting companies when fish is evaluated at the fish auction: skin or surface appearance, bruises or discolouration, and texture (Karlsen et al., 2015; Table 2). Such a scheme provides a finer degree of discrimination than the EU quality grading scheme currently in use (EU, 1996). The scores for each attribute in the Processed fish-damage-index scheme ranged from 0 for flawless to 2 for most severe (Table 2, see Fig. 2 for examples of ratings). Gaping is when the individual flakes of muscle come apart giving the fish flesh a broken appearance. A fish in pre-rigor or rigor stage is considered to be of good freshness by the buyer and was ranked as flawless for the attribute 'texture'. Assessments included three processing steps, whole fish, after skinning, and after filleting (Fig. 1). Skinning and filleting were done with a skinner (Steen ST 111) and by hand, respectively, by a person specialized in hand-filleting of plaice working at the factory. Visual and tactile assessments of fish were conducted by the same quality representative under the guidance of a scientist who did not attend the assessment at sea. Both were unaware of how each specific fish had been caught. The Processed fishdamage-index was then calculated for each individual by summing scores for all attributes. 
The Processed fish-damage-index scale ranged from 0 for flawless to 6 for most severe.

In order to look at the relationship between CDi and Processed fish-damage-index, we assessed fish using both schemes on the same individuals for the four last days of the sea trial, i.e., 64 fish (4 days x 2 soaks x 8 fish). However, for simplifying tracking of fish, assessment of fish using CDi was run a second time for this purpose after landing and not directly on deck. It was therefore not possible to assess the attribute 'Dead in gear' in that case.

More objectives quality assessments methods such as computer vision evaluation of loin colour (Erikson \& Misimi, 2008) or texture analyzer (Einen \& Thomassen, 1998) have been developed, but visual assessment was chosen for CDi as it can easily be implemented on a vessel at sea, and for the Processed fish-damage-index as this is how the exporters and processing companies currently evaluate fish.

\subsection{Statistical analysis}

Cumulative link mixed modelling was used to model CDi as a function of soak time and fish length. It is a generalization of logistic regression which models ordinal responses, allows for random effects, and tends to work well for sensometric data (Christensen \& Brockhoff, 2013). To model CDi, i.e., the response variable $Y_{i}$ with a value from 0 to 12 representing the degree of fish damage summed for all attributes, as a function of soak time and fish length, the full cumulative link mixed model fitted to the data was:

$\operatorname{logit}\left(P\left(Y_{i} \leq j\right)\right)=\theta_{j}-\beta_{1}\left(\operatorname{soak}_{i}\right)-\beta_{2}\left(\right.$ length $\left._{i}\right)-u\left(\operatorname{set}_{i}\right)$

with $i=1, \ldots, n, j=1, \ldots, J-1$ and $u\left(\operatorname{set}_{i}\right) \sim N\left(\sigma_{u}^{2}\right)$.

This is a model for the cumulative probability of the $i^{\text {th }}$ rating falling in the $j^{\text {th }}$ category or below, where $i$ index all $n$ observations (fish) and $j$ index the response categories $(J=13$ ). The parameters $\beta_{1}\left(\operatorname{soak}_{i}\right)$ and $\beta_{2}\left(\right.$ length $\left.h_{i}\right)$ describe the effect of the explanatory variables, respectively soak time and fish length, on the log odds of response in category $j$ or below, and are assumed to have the same effect for each of the $J-1$ cumulative logits. The random effect of sets $u\left(\right.$ set $\left._{i}\right)$ is added to the model to avoid pseudo-replication by accounting for mechanisms that could generate positive association among clustered observations (Fryer, 1991; Millar \& Anderson, 2004). The random effect is assumed to be the same for each cumulative probability, independent and normal identically distributed. At each setting of the explanatory variables, the multicategory model assumes that the counts in the categories of 
the outcome have a multinomial distribution and $\left\{\theta_{j}\right\}$ are the threshold parameters. Maximum likelihood estimates of the parameters, i.e., the values of the parameters of a chosen model which make the observed data most likely, were provided using the adaptive Gauss-Hermite quadrature method with 10 quadrature nodes (Christensen, 2015). A condition number of the Hessian not larger than $10^{6}$ was an indication of having a successful model (Christensen, 2015). Four models were considered for selection of a final one, the full model (1a) and three simpler nested versions (1b, 1c, 1d):

$\operatorname{logit}\left(P\left(Y_{i} \leq j\right)\right)=\theta_{j}-\beta_{2}\left(\right.$ length $\left._{i}\right)-u\left(\right.$ set $\left._{i}\right)$

$\operatorname{logit}\left(P\left(Y_{i} \leq j\right)\right)=\theta_{j}-\beta_{1}\left(\operatorname{soak}_{i}\right)-u\left(\right.$ set $\left._{i}\right)$

$\operatorname{logit}\left(P\left(Y_{i} \leq j\right)\right)=\theta_{j}-\beta_{1}\left(\operatorname{soak}_{i}\right)-\beta_{2}\left(\right.$ length $\left._{i}\right)$

Significance of the parameters of the full model (1a) was tested using the likelihood ratio statistic with the Anova method, which measures the evidence in the data for extra complexity in the full model relative to a simpler model. It is not relevant to test whether the thresholds are equal to zero, so no p-values were provided for this test (Christensen, 2015). Concordance with the log-likelihood and the Akaike Information Criterion were used for selecting the final model (Akaike, 1974). The predicted probabilities of the final model were computed at different experimental conditions for illustrative purpose.

In the same manner, the full cumulative link mixed model fitted to the data to model Processed fish-damage-index as a function of processing step was:

$\operatorname{logit}\left(P\left(Y_{i} \leq j\right)\right)=\theta_{j}-\beta\left(\right.$ step $\left._{i}\right)-u\left(\right.$ fish $\left._{i}\right)$

with $i=1, \ldots, n, j=1, \ldots, J-1$ and $u\left(f i s h_{i}\right) \sim N\left(\sigma_{u}^{2}\right)$.

$i$ index all $n$ observations (fish), $j$ indexes the response categories $(J=7)$ and $\beta$ step $_{i}$ ) describes the effect of the processing step on the log odds of response in category $j$ or below, with filleting as baseline. The random effect of fish $u\left(f i s h_{i}\right)$ was added to account for the fact that assessments throughout processing steps were observed on the same fish. Three models were considered for selection of a final one, the full model (2a) and two simpler nested versions (2b, 2c):

$\operatorname{logit}\left(P\left(Y_{i} \leq j\right)\right)=\theta_{j}-u\left(\right.$ fish $\left._{i}\right)$ 
$\operatorname{logit}\left(P\left(Y_{i} \leq j\right)\right)=\theta_{j}-\beta\left(\right.$ step $\left._{i}\right)$

One can consider that CDi and Processed fish-damage-index represent an underlying variable, unobserved and unmeasurable, integrating the many ways in which each attribute interact to determine the overall quality condition of a fish. Hence, interest here was in CDi and Processed fish-damage-index, and not in the rating of single attributes, which were therefore not modelled. Detailed results are given as supplementary material. All calculations and graphs were conducted in R (R, 2015) using the packages 'ordinal’ (Christensen, 2015) and 'ggplot2' (Wickham, 2009).

\section{Results and discussion}

\subsection{Catch-damage-index}

\subsubsection{Level of catch damage of newly caught fish}

Fleets were set at an average depth of $5.4 \mathrm{~m}$ (standard deviation: $\pm 0.6 \mathrm{~m}$ ) representative of shallow summer fishing grounds in the Danish costal gillnet fishery. Of a total of 1601 caught plaice, 1338 individuals from 62 different sets (3 soak times x 3 fleets $x 7$ days) were assessed onboard the fishing vessel. One set was without fish. Fish for which assessment was uncertain or data were missing, were not used in the analysis (263 individuals). Most of the assessed fish (99\%) presented moderate or severe damage for at least one attribute. The CDi scores observed ranged from 0 to 9, i.e., none of the fish scored in the highest rating categories (1012). The proportion of fish grading for score 2 at the attribute level were low except bruises, for which $40 \%$ were found in the body part. Bruises are a result of an accumulation of blood residue appearing as dark patches on the blind side of flatfish as a result of meshing, the fact that the fish struggled in the net, and handling (Botta et al., 1987; Özyurt et al., 2007).

\subsubsection{Effect of soak time on Catch-damage-index}

The average soak time was $23.8 \mathrm{~h}$ (standard deviation: $\pm 1.2 \mathrm{~h}$ ) for the $24 \mathrm{~h}$ fleets, $10.7 \mathrm{~h}$ ( $\pm 0.9 \mathrm{~h})$ for the $12 \mathrm{~h}$ day fleets, and $12.4 \mathrm{~h}( \pm 1.1 \mathrm{~h})$ for the $12 \mathrm{~h}$ night fleets. The coefficient for soak was significant and positive indicating that higher CDi scores were more likely for 24h than for $12 \mathrm{~h}$ soaks, i.e., fish soaked for $24 \mathrm{~h}$ were assessed to have a lower quality than those soaked for 12h (Table 3, Fig. 3). This is in line with observations in other gill- and trammel nets studies (Acosta, 1994; Auclair, 1984; Borges et al., 2001; Hickford \& Schiel, 1996). 
Higher CDi scores for $24 \mathrm{~h}$ soaks were not due to a greater damage severity at the attribute level, i.e., in both soaks the same proportion of assessed fish (46\%) scored 2 for at least one attribute, but to the accumulation of damages in several attributes. There were proportionally more fish grading in higher scores when caught in the $24 \mathrm{~h}$ than $12 \mathrm{~h}$ sets regarding the three following attributes. Longer soak extended the probability for a caught-fish to be rubbed against the netting and show gear damage (93\% for $24 \mathrm{~h}$ and $85 \%$ for $12 \mathrm{~h}$ ) and skin abrasion (60\% and 54\%), with scale loss damages mainly located in the surroundings of yarn marks and associated with gear damages. Biting (43\% and 34\%), mostly located on fins and tail (96\% of the damaged fish), was caused by scavengers and predators which had an increased chance to feed on the caught-fish at longer soak (Auclair, 1984; Perez \& Wahrlich, 2005; Petrakis et al., 2010; Santos et al., 2002). Pressure damages (31\% and 23\%) were a result of the fish being squeezed close to the pelvic fin when the fisherman untangled it from the net, which severity was expected to depend on mesh size and twine characteristics of the net, but which could also be facilitated in damaged fish, i.e., soaked for $24 \mathrm{~h}$.

There were no differences in mortality whereas this has been observed in other gill- and trammel net studies (Bettoli \& Scholten, 2006; Buchanan et al., 2002; Chopin et al., 1996; Losanes, Matuda, \& Fujimori, 1992). Our mortality rate of 8.4\% was lower than that reported in other studies using similar gears at comparable water temperature conditions (Batista et al., 2009; Bettoli \& Scholten, 2006; Chopin, Arimoto, \& Inoue, 1996; Murphy, Heagey, Neugebauer, Gordon, \& Hintz, 1995; Schmalz \& Staples, 2014), most likely because plaice is a robust species, giving here mortalities in range with those observed in trawl-caught plaice (Revill, Broadhurst, \& Millar, 2013).

\subsubsection{Effect of soak time compared to that of fish length}

The coefficient for fish length was significant and negative indicating that higher CDi scores were less likely for larger fish, i.e., larger fish were assessed to have a higher quality than smaller fish (Table 3, Fig. 3). There were proportionally more small fish rating in higher scores for skin abrasion (75\% for $20-29 \mathrm{~cm}$ and $31 \%$ for $40-53 \mathrm{~cm}$, respectively) and biting (41\% and 26\%). Smaller fish were more likely caught with the netting behind the gill and around the largest part of the body engendering scale loss, contrary to larger fish which can be caught by the head region (snagging). The relatively lower mass of smaller plaice compared to larger ones could render them more susceptible to injuries such as biting as suggested by 
Revill et al. (2013).

\subsubsection{Effect of soak time compared to between-sets variation}

The estimated standard deviation of the random effects suggested substantial heterogeneity among sets in their response probabilities, i.e., fish of the same size and soaked for the same duration had lower or higher CDi depending on the set they were caught in (Table 3, Fig. 3). Information on day and fleet were pooled in the set random effect. Fish length did not vary between sets (mean per set \pm standard deviation: $31.4 \pm 1.36 \mathrm{~cm}$ ). A daily systematic effect was not likely in our study, which was conducted over a relatively short time scale. Even though all variables not of interest were kept as constant as possible, for example bottom type or depth, local bottom disparities, varying small-scale meteorological conditions such as wind or current, or varying net geometry from one fleet to the other may account for the large variation among sets. Besides, the time interval from the fleet is soaked until the fish is caught in the net may vary largely from one set to the other and have profound consequences for the damage level.

\subsection{Processed fish-damage-index}

\subsubsection{Level of damage of landed fish}

A total of 80 landed fish were assessed (8 fish x 2 soak times $x 5$ days) as whole, skinned and filleted fish. The Processed fish-damage-index scores observed ranged from 0 to 4 for all attributes, i.e., none of the fish scored in the highest rating categories (5-6). All fish assessed were in a pre-rigor or rigor stage, and few fish (a maximum of $2.5 \%$ per attribute of all fish assessed) scored in the highest rates regarding bruises or surface at the three processing steps. In the opinion of the local expert at the fish factory, the overall quality of the landed fish in this study was very good. There may be several reasons for this. Fish in very bad conditions and the smallest ones, more prone to damage, were not landed. The weather conditions during the sea trials were good. Appropriate handling and storage are important to keep the quality of fish at a high level after capture (Hopper et al., 2003). Fish were correctly bled, which reduces the blood remains in the flesh and improves the fillet whiteness (Ashie, Smith, Simpson, \& Haard, 1996; Roth, Torrissen, \& Slinde, 2005; Olsen et al., 2014).

\subsubsection{Relationship between CDi and Processed fish-damage-index}


All fish randomly sampled for further analysis at the fish factory showed low score in the CDi scheme, ranging from 1 to 6 (on a scale of 0 to 10 without considering the attribute 'Dead in gear'), as well as in the Processed fish-damage-index scheme for whole fish, ranging from 0 to 3 (on a scale of 0 to 6). Results of the comparison showed a positive relationship between CDi and Processed fish-damage-index for whole fish. Whole fish with low CDi scores, from 1 to 2, showed a median Processed fish-damage-index score of 1 and those with higher CDi scores, from 3 to 6 , a median score of 2.

\subsubsection{Processed fish-damage-index throughout processing}

Comparison of Processed fish-damage-index throughout the three observed steps, i.e., whole, skinned and filleted fish, was done with filleting as baseline, therefore comparing whole and skinned fish, respectively, with filleted fish.

The coefficient for whole fish was significant and positive indicating that higher damage index scores were more likely for whole than for filleted fish, i.e., filleted fish had a higher quality than whole fish (Table 3, Fig. 4). Yarn marks and scale loss in whole fish may not be severe enough to impair the filleted fish. Damage may also be located in an area which is normally trimmed at processing (fins, tail) such as with bruises, which was supported by our results (55\% and 39\% of bruised whole and filleted fish, respectively).

The coefficient for skinned fish was significant and negative indicating that higher Processed fish-damage-index scores were less likely for skinned than for filleted fish, i.e., skinned fish had a higher quality than filleted fish (Table 3, Fig. 4).

Severe gaping and jellied condition, i.e., waterish meat which is not related to the catching method (Templeman \& Andrews, 1956), were only visible at the fillet level. Gaping could be caused by rigor, injuries or rough handling, for instance during machine skinning of fish in rigor (Stroud, 1981). Some bruises were also not found before the fish was filleted. Our bruising rate in filleted fish (39\%) was in line with observations on fillets from gillnet-caught cod (34\% with bruises exceeding 2cm) and on trawl-caught round and flatfish (27 to 33\% with bruises or blood spots) (Botta et al., 1987; Digre et al., 2010; Karlsen et al., 2015).

\subsubsection{Effect of processing step compared to that of between-fish variation}

The effect of processing step was on the same order of magnitude as the random variation. The estimated standard deviation of the random effects suggested substantial heterogeneity 
among fish (Table 3, Fig. 4). Such intraspecific variation is in agreement with a higher variability of a catch-damage-index for plaice compared to other species in Depestele et al. (2014). There can be several reasons for this. Analysis of the CDi showed an effect of fish length on the quality of whole fish, which was also observed in processed fish by Love (1975) who found more severe surface drying in smaller fish and more gaping, whereas larger fish are more prone to show jellied condition (Templeman \& Andrews, 1956). Some fish are also inherently softer than others, e.g. starving or spawning individuals, and therefore more prone to gaping when skinned or filleted (Esaiassen et al., 2013; Love, 1975).

\subsection{Implications for the coastal gillnetting fishery}

\subsubsection{Effect of soak time on catch damage and catch rate}

The effect of soak time was calculated to be equal to the effect of a fish-length difference of $8 \mathrm{~cm}(0.54 / 0.07)$, and was on the same order of magnitude as the between-sets random variation, making a change in soak time not so substantial for improving plaice quality in coastal gillnetting. The effect of soak time on catch damage is expected to be higher in other species or longer soak durations.

Soak time should also guarantee an acceptable catch rate of commercial fish to optimize landings with regard to fishing effort, fuel consumption and labour cost (Hickford \& Schiel, 1996; Hopper et al., 2003). There were no difference between soaks in the number of target species caught (plaice above the minimum landing size) (unpublished results), which is in line with previous studies suggesting a relationship between soak time and catch size for short soak times (up to 6h) but none for longer soak times (Acosta, 1994; Gonçalves et al., 2008; Hickford \& Schiel, 1996; Losanes et al., 1992; Minns \& Hurley, 1988; Rotherham et al., 2006; Schmalz \& Staples, 2014).

\subsubsection{From fish quality to commerciality}

The CDi scheme was in agreement with the quality rankings used at the fish auction regarding commerciality of plaice, where fish must be free of pressure marks and injuries in category Extra, free of blemishes and bad discolouration in category A, and a small proportion of fish with more serious pressure marks and superficial injuries in category B (EU, 1996). An evaluation of the physical damages in relation to commerciality is also found in the scale of damaged fish developed by Petrakis et al. (2010) that can be related to our 
assessment. Fish with no or moderate damages, e.g. eyes and gills eaten or small bites, i.e., corresponding to the low and medium CDi ratings, are usually fit for commercial purpose, but not those with severe damage, e.g. the abdominal area eaten or with only skin and skeleton remain, i.e., corresponding to the highest CDi ratings.

The fish will either be sold as whole fish or as raw material for further processing. Most of the processed plaice produced in Denmark is sold as frozen fillets (FAO, 2014). Bruises do not impair the taste of fillets, but they are not attractive to consumers, and the fish processing factory would usually remove the part of the flesh with these marks, which reduce fillet weight and final profit (Roth et al., 2007; Kenney et al., 2015). Marks on the fins and tail may not impair the yield in fillet as it is standard procedure to remove these parts during filleting. Minor marks on the thicker part of the fillet can be accepted and used for products of lower value compared with flawless fillets, but fillets with major marks on the thicker part or severe gaping are minced and sold as low quality product or destructed (Margeirsson, Nielsen, Jónsson \& Arason, 2006).

Other factors than quality may account for most of variation in prices, such as fish size, with lower prices per kg for small plaice, or market demand, but prices for plaice in Denmark are in general low and show little variation (Lawler, 2003; Hopper et al., 2003; Tsikliras \& Polymeros, 2014).

\subsubsection{Conclusion}

Cumulative link mixed modelling worked well with our semi-quantitative indices, but it was difficult to directly estimate processed product quality from catch damage as some damage on whole fish had no effect on the fillet produced whereas others may only be visible at the fillet level.

Damage in fish was significantly more likely for whole than filleted fish. Selling whole fish directly to consumers has however proven worthy for some Danish coastal gillnetters, for which improvement in whole fish quality could make a difference. Damage in fish was significantly more likely for longer soak times but effects were comparable to those of fish length and between-sets, making a change in soak time not so substantial for improving plaice quality in coastal gillnetting. Further investigations could look into the factors responsible for the between-sets random variation.

\section{Acknowledgements}


The authors wish to thank Kim Skovsmose, the skipper of HG5 Skovsmose, the local fishermen organization, and Reinhardt Jensen from DTU Aqua, for their help before and during the cruise. The authors also wish to thank Susanne Kjærgaard Majid from Keka Fisk ApS for her time and expertise in fish assessment. Jordan P. Feekings and Grete Dinesen (DTU Aqua) made valuable comments regarding English writing and background information on invertebrates, respectively. The Danish Ministry of Food, Agriculture and Fisheries funded the present study ('Skånfisk project'), but was not involved in the conduct of the research or preparation of the article.

\section{References}

Acosta, A. R. (1994). Soak time and net length effects on catch rate of entangling nets in coral-reef areas. Fish. Res., 19, 105-119.

Akaike, H. (1974). A new look at the statistical model identification. IEEE Trans. Autom. Control, 19, 716-723.

Andersen, B.S., Ulrich, C., Eigaard, O.R., \& Christensen, A.-S. (2012). Short-term choice behaviour in a mixed fishery: investigating métier selection in the Danish gillnet fishery. ICES J. Mar. Sci., 69, 131-143.

Ashie, I.N.A., Smith, J.P., Simpson, B.K., \& Haard, N.F. (1996). Spoilage and shelf life extension of fresh fish and shellfish, Crit. Rev. Food Sci. Nutr., 36, 87-121.

Auclair, G. (1984). Comparative study of trawl and gillnet effects on the quality of fish. Can. I. Food Sc. Tech. J., 17.

Benoît, H.P., Hurlbut, T., \& Chassé, J. (2010). Assessing the factors influencing discard mortality of demersal fishes using a semi-quantitative indicator of survival potential. Fish Res., 106, 436-447.

Bettoli, P.W., \& Scholten, G.D. (2006). Bycatch rates and initial mortality of paddlefish in a commercial gillnet fishery. Fish. Res., 77, 343-347.

Batista, M.I., Teixeira, C.M., \& Cabral, H.N. (2009). Catches of target species and bycatches of an artisanal fishery: the case study of a trammel net fishery in the Portuguese coast. 
Borges, T.C., Erzini, K., Bentes, L., Costa, M.E., Gonçalves, J.M.S., Lino, P.G., Pais, C., \& Ribeiro, J. (2001). By-catch and discarding practices in five Algarve (southern Portugal) métiers. J. Appl. Ichthyol., 17, 104-114.

Botta, J.R., Bonnell, G., Squires, B.E. (1987). Effect of method of catching and time of season on sensory quality of fresh raw Atlantic cod (Gadus morhua). J. Food Sci., 52, 928-931.

Buchanan, S., Farrell, A.P., Fraser, J., Gallaugher, P., Joy, R., \& Routledge, R. (2002). Reducing gill-net mortality of incidentally caught Coho Salmon, N. Am. J. Fish. Manage., 22, 1270-1275.

Christensen, R. H. B. (2015). Ordinal - Regression Models for Ordinal Data. R package version 2015.

Christensen, R.H.B., \& Brockhoff, P.B. (2013). Analysis of sensory ratings data with cumulative link models. J. Soc. Francaise Stat. Rev. Stat. Appl., 154, 58-79.

Chopin, F.S., Arimoto, T., \& Inoue, Y. (1996). A comparison of the stress response and mortality of sea bream Pagrus major captured by hook and line and trammel net. Fish. Res., 28, 277-289.

Denton, W. (2003). Fish quality labelling and monitoring: Getting it right at the start. In J. B. Luten, J. Oehlenschläger, \& G. Ólafsdóttir (Eds.), Quality of fish from catch to consumer: labelling, monitoring and traceability (pp. 101-111). Wageningen: Wageningen Academic Publishers.

Depestele, J., Desender, M., Benoît, H.P., \& Polet, H. (2014). Short-term survival of discarded target fish and non-target invertebrate species in the "eurocutter” beam trawl fishery of the southern North Sea. Fish. Res., 154, 82-92.

Digre, H., Hansen, U. J., \& Erikson, U. (2010). Effect of trawling with traditional and 'T90' trawl codends on fish size and on different quality parameters of cod Gadus morhua and haddock Melanogrammus aeglefinus. Fish. Sci., 76, 549-559. 
Digre, H., Tveit, G.M., Solvang-Garten, T., Eilertsen, A., \& Aursand, I.G. (2016). Pumping mackerel (Scomber scombrus) onboard purse seiners, the effect on mortality, catch damage and fillet quality. Fish. Res., 176, 65-75.

Einen, O., \& Thomassen, M.S. (1998). Starvation prior to slaughter in Atlantic salmon (Salmo salar): II. White muscle composition and evaluation of freshness, texture and colour characteristics in raw and cooked fillets. Aquaculture, 169, 37-53.

Erikson, U., \& Misimi, E. (2008). Atlantic salmon skin and fillet color changes effected by perimortem handling stress, rigor mortis, and ice storage. J. Food Sci. 73, 50-59.

Esaiassen, M., Akse, L., \& Joensen, S. (2013). Development of a Catch-damage-index to assess the quality of cod at landing. Food Control, 29, 231-235.

E.U. (1996). Council Regulation (EC) No 2406/96 of 26 November 1996 laying down common marketing standards for certain fishery products. OJ, L334, pp. 1-15.

E.U. (2013). Regulation No 227/2013 of the European Parliament and of the Council of 13 March 2013 amending Council Regulation (EC) No 850/98 for the conservation of fishery resources through technical measures for the protection of juveniles of marine organisms and Council Regulation (EC) No 1434/98 specifying conditions under which herring may be landed for industrial purposes other than direct human consumption. OJ, L78, p. 1-22.

FAO. (2014). Fishery and Aquaculture Statistics. Global Fisheries commodities production and trade 1976-2011 (FishstatJ). Retrieved from http://www.fao.org/fishery/statistics/software/fishstatj/en.

Fryer, R.J. (1991). A model of between-haul variation in selectivity. ICES J. Mar. Sci., 48, 281-290.

Gonçalves, J. M. S., Bentes, L., Coelho, R., Monteiro, P., Ribeiro, J., Correia, C., Lino, P. G., \& Erzini, K. (2008). Non-commercial invertebrate discards in an experimental trammel net fishery. Fish. Manag. Ecol., 15, 199-210.

Hickford, M. J. H., \& Schiel, D. R. (1996). Gillnetting in southern New Zealand: Duration 
effects of sets and entanglement modes of fish. Fish. Bull., 94, 669-677.

Hopper, A. G., Batista, I., Nunes, M. L., Abrantes, J., Frismo, E., van Slooten, P., SchelvisSmit, A. A. M., Dobosz, E., Lopez, E. M., Cibot, C., \& Beveridge, D. (2003). Good manufacturing practice on European fishing vessels. In J. B. Luten, J. Oehlenschläger, \& G. Ólafsdóttir (Eds.), Quality of Fish from Catch to Consumers (pp. 113-126). Wageningen: Wageningen Academic Publishers.

Karlsen, J.D., Krag, L.A., Albertsen, C.M., Frandsen, R.P. (2015). From fishing to fish processing: separation of fish from crustaceans in the Norway lobster-directed multispecies trawl fishery improves seafood quality. PLoS ONE 10 (11): e0140864.

Kenney, J. L., Rahman, T., Manuel, H., \& Winge, P. D. (2015). Bruising patterns in commercially harvested yellowtail flounder (Limanda ferruginea). Fish. Res., 172, 79-84.

Lawler, I. (2003). Introducing GMP at sea. Does it pay? In J. B. Luten, J. Oehlenschläger, \& G. Ólafsdóttir (Eds.), Quality of fish from catch to consumer: labelling, monitoring and traceability (pp. 151-157). Wageningen: Wageningen Academic Publishers.

Losanes, L.P, Matuda, K., \& Fujimori, Y. (1992). Outdoor tank experiments on the influence of soak time on the catch efficiency of gillnets and entangling nets. Fish. Res., 15, 217227.

Love, R. M. (1975). Variability in Atlantic cod (Gadus morhua) from the Northeast Atlantic: a review of seasonal and environmental influences on various attributes of the flesh. J. Fish. Res. Board Can., 32, 2333-2342.

Millar, R. B., \& Anderson, M. J. (2004). Remedies for pseudoreplication. Fish. Res., 70, 397407.

Margeirsson, S., Nielsen, A.A., Jónsson, G.R., \& Arason, S. (2006). Effect of catch location, season and defects on value of Icelandic cod (Gadus morhua) products. In J.B. Luten, C. Jacobsen, K. Bekaert, A. Sæbø, J. \& Oehlensläger (Eds.), Seafood Research from Fish to Dish. Quality, Safety and Processing of Wild and Farmed Fish (pp. 265-274). Wageningen: Wageninen Academic publishers. 
Margeirsson, S., Jonsson, G. R., Arason, S., \& Thorkelsson, G. (2007). Influencing factors on yield, gaping, bruises and nematodes in cod (Gadus morhua) fillets. J. Food Eng., 80, 503508.

Martinsdóttir, E., Luten, J. B., Schelvis-Smit, A. A. M., \& Hyldig, G. (2003). Developments of QIM - past and future. In J. B. Luten, J. Oehlenschläger, \& G. Ólafsdóttir (Eds.), Quality of fish from catch to consumer: labelling, monitoring and traceability (pp. 265272). Wageningen: Wageningen Academic Publishers.

Minns, C.K., \& Hurley, D.A. (1988). Effects of net length and set time on fish catches in gill nets. N. Am. J. Fish. Manage., 8, 216-223.

Morandeau, G., Macher, C., Sanchez, F., Bru, N., Fauconnet, L., \& Caill-Milly, N. (2014). Why do fishermen discard? Distribution and quantification of the causes of discards in the Southern Bay of Biscay passive gear fisheries. Mar. Policy, 48, 30-38.

Murphy, M.D., Heagey, R.F., Neugebauer, V.H., Gordon, M.D., Hintz, J.L. (1995). Mortality of Spotted Seatrout Released from GillNet or Hook-and-Line Gear in Florida. N. Am. J. Fish. Manage., 15, 748-753.

Olsen, S. H., Joensen, S., Tobiassen, T., Heia, K., Akse, L., \& Nilsen, H. (2014). Quality consequences of bleeding fish after capture. Fish. Res., 153, 103-107.

Olsen, S.H., Tobiassen, T., Akse, L., Evensen, T.H., \& Midling, K.Ø. (2013). Capture induced stress and live storage of Atlantic cod (Gadhus morhua) caught by trawl: consequences for the flesh quality. Fish. Res., 147, 446-453.

Özogul, Y., \& Özogul, F. (2004). Effects of slaughtering methods on sensory, chemical and microbiological quality of rainbow trout (Onchorynchus mykiss) stored in ice and MAP. Eur. Food Res. Technol., 219, 211-216.

Özyurt, G., Özogul, Y., Özyurt, C. E., Polat, A., Özogul, F., Gökbulut, C., Ersoy, B., \& Küley, E. (2007). Determination of the quality parameters of pike perch Sander lucioperca caught by gillnet, longline and harpoon in Turkey. Fish. Sci., 73, 412-420.

Petrakis, G., Cheilari, A., \& Cambiè, G. (2010). A scale of damaged fish (SDF). Rapp. 
Perez, J.A.A., \& Wahrlich, R. (2005). A bycatch assessment of the gillnet monkfish Lophius gastrophysus fishery off southern Brazil. Fish. Res., 72, 81-95.

R Core Team. (2015). R: A language and environment for statistical computing. R Foundation for Statistical Computing, Vienna, Austria.

Revill, A.S., Broadhurst, M.K., \& Millar, R.B. (2013). Mortality of adult plaice, Pleuronectes platessa and sole, Solea solea discarded from English Channel beam trawlers. Fish. Res., 147, 320-326.

Rotabakk, B.T., Skipnes, D., Akse, L., \& Birkeland, S. (2011). Quality assessment of Atlantic cod (Gadus morhua) caught by longlining and trawling at the same time and location. Fish. Res., 112, 44-51.

Roth, B., Nortvedt, R., Stien, L. H., Schelvis-Smit, R., Imsland, A., \& Foss, A. (2007).

Exsanguination of turbot and the effect on fillet quality measured mechanically, by sensory evaluation, and with computer vision. J. Food Sci., 72, 525-531.

Rotherham, D., Gray, C.A., Broadhurst, M.K., Johnson, D.D., Barnes, L.M., \& Jones, M.V. (2006). Sampling estuarine fish using multi-mesh gill nets: Effects of panel length and soak and setting times. J. Exp. Mar. Biol. Ecol., 331, 226-239.

Santos, M. N., Gaspar, M. B., Monteiro, C. C., Vasconcelos, P. (2002). Gill net and long-line catch comparisons in a hake fishery: the case of southern Portugal. Sci. Mar., 66, 433-441.

Schmalz, P.J., \& Staples, D.F. (2014). Factors affecting walleye catch in short-term gill-net sets in a large Minnesota lake. N. Am. J. Fish. Manage., 31, 12-22.

Stroud, G.D., 1981. Rigor in fish, the effect on quality (Torry Advisory Note No. 36). Retrieved from FAO: http://www.fao.org/wairdocs/tan/x5914e/x5914e00.htm\#Contents

Suuronen, P., Chopin, F., Glass, C., Løkkeborg, S., Matsushita, Y., Queirolo, D., \& Rihan, D. (2012). Low impact and fuel efficient fishing - Looking beyond the horizon. Fish. Res., 119-120, 135-146. 
524 Templeman, W., \& Andrews, G.L., 1956. Jellied condition in the American plaice

525 Hippoglossoides platessoides (Fabricius). J. Fish. Res. Board. Can., 13, 147-182.

526 Tsikliras, A. C., \& Polymeros, K. (2014). Fish market prices drive overfishing of the 'big 527 ones’. PeerJ, 2:e638.

528 Wickham, H. (2009). ggplot2: elegant graphics for data analysis. New York: Springer. 


\section{Table 1.}

Assessment scheme showing the attributes and rating scores used to calculate the Catchdamage-index for fish assessed onboard the fishing vessel.

\begin{tabular}{|c|c|c|}
\hline Damage & Description & Score \\
\hline \multirow[t]{2}{*}{ Dead in gear } & Live & 0 \\
\hline & Dead & 2 \\
\hline \multirow[t]{3}{*}{ Gear damage } & No marks & 0 \\
\hline & Stripes, fin damage & 1 \\
\hline & Deep marks, crushing & 2 \\
\hline \multirow[t]{3}{*}{ Bruises } & No & 0 \\
\hline & In fin/tail part & 1 \\
\hline & In body part & 2 \\
\hline \multirow[t]{3}{*}{ Skin abrasion } & No & 0 \\
\hline & Minor & 1 \\
\hline & Severe, perforated skin & 2 \\
\hline \multirow[t]{3}{*}{ Pressure injuries } & No & 0 \\
\hline & Squeezed in fin/tail part & 1 \\
\hline & In body part & 2 \\
\hline \multirow[t]{3}{*}{ Biting injuries* } & No & 0 \\
\hline & Damaged fins/tail & 1 \\
\hline & Deep wounds/bite marks & 2 \\
\hline
\end{tabular}

*Some of the recorded injuries could be due to fraying and not biting. 


\section{Table 2.}

Assessment scheme showing the attributes and rating scores used to calculate the Processed fish-damage-index for fish at three different processing steps.

\begin{tabular}{llll}
\hline Step & Attribute & Description & Score \\
\hline Whole & Surface & Glossy, no scale loss & 0 \\
& & Bright, few scale loss & 1 \\
& & Dull, many scale loss & 2 \\
& Bruises & No & 0 \\
& & Few & 1 \\
& & Many & 2 \\
& Texture & Pre-rigor or rigor & 0 \\
& & Firm & 1 \\
Skinned & Surface & Soft & 2 \\
& & Smooth & 0 \\
& & Few gapings & 1 \\
& Bruises & Many gapings & 2 \\
& & Few & 0 \\
& & Many & 1 \\
& Texture & Pre-rigor or rigor & 2 \\
& & Firm & 0 \\
Filleted & Surface & Soft & 1 \\
& & Smooth & 2 \\
& & Few gapings & 0 \\
& Bruises & Many gapings & 1 \\
& & No & 2 \\
& & Few & 0 \\
& & Many & 1 \\
& Texture & Normal & 2 \\
& & Jelly & 0 \\
& & & 2 \\
\hline
\end{tabular}




\section{Table 3.}

Maximum likelihood estimates and standard errors (S.E.) of the parameters in the final model for the CDi, i.e., soak time $\widehat{\beta}_{1}\left(\operatorname{soak}_{\mathrm{i}}\right)$, fish length $\widehat{\beta}_{2}\left(\operatorname{length}_{\mathrm{i}}\right)$, set $\widehat{\sigma}_{\mathrm{u}\left(\operatorname{set}_{\mathrm{i}}\right)}^{2}$ and thresholds $\left\{\widehat{\theta}_{\mathrm{J}}\right\}$, and the Processed fish-damage-index, i.e., processing step $\widehat{\beta}\left(\operatorname{step}_{\mathbf{i}}\right)$, fish $\widehat{\sigma}_{\mathbf{u}\left(f_{i s h}\right)}^{2}$ and thresholds $\left\{\widehat{\theta_{3}}\right\}$ ), and their significance levels (p-value) based on the likelihood ratio test. No p-values are provided for the thresholds.

\begin{tabular}{llll}
\hline Parameter & Estimate & S.E. & p-value \\
\hline$\underline{\text { CDi }}$ & & & \\
Soak & 0.54 & 0.26 & $<0.05$ \\
Fish size & -0.070 & 0.012 & $<0.001$ \\
Set & 0.85 & NA & $<0.001$ \\
Thresholds & -6.65 & 0.48 & \\
& -4.64 & 0.42 & \\
& -3.26 & 0.41 & \\
& -1.84 & 0.40 & \\
& -0.52 & 0.40 & \\
& 0.99 & 0.41 & \\
& 2.24 & 0.43 & \\
& 3.79 & 0.52 & \\
Processed fish-damage-index & \\
Step: whole & 2.00 & 0.37 & $<0.001$ \\
Step: skinned & -1.24 & 0.39 & $<0.001$ \\
Fish & 1.68 & NA & $<0.001$ \\
Thresholds & 0.059 & 0.32 & \\
& 2.37 & 0.39 & \\
& 5.37 & 0.61 & \\
& 7.52 & 1.12 & \\
\hline
\end{tabular}


Fig. 1. Experimental design and data collection

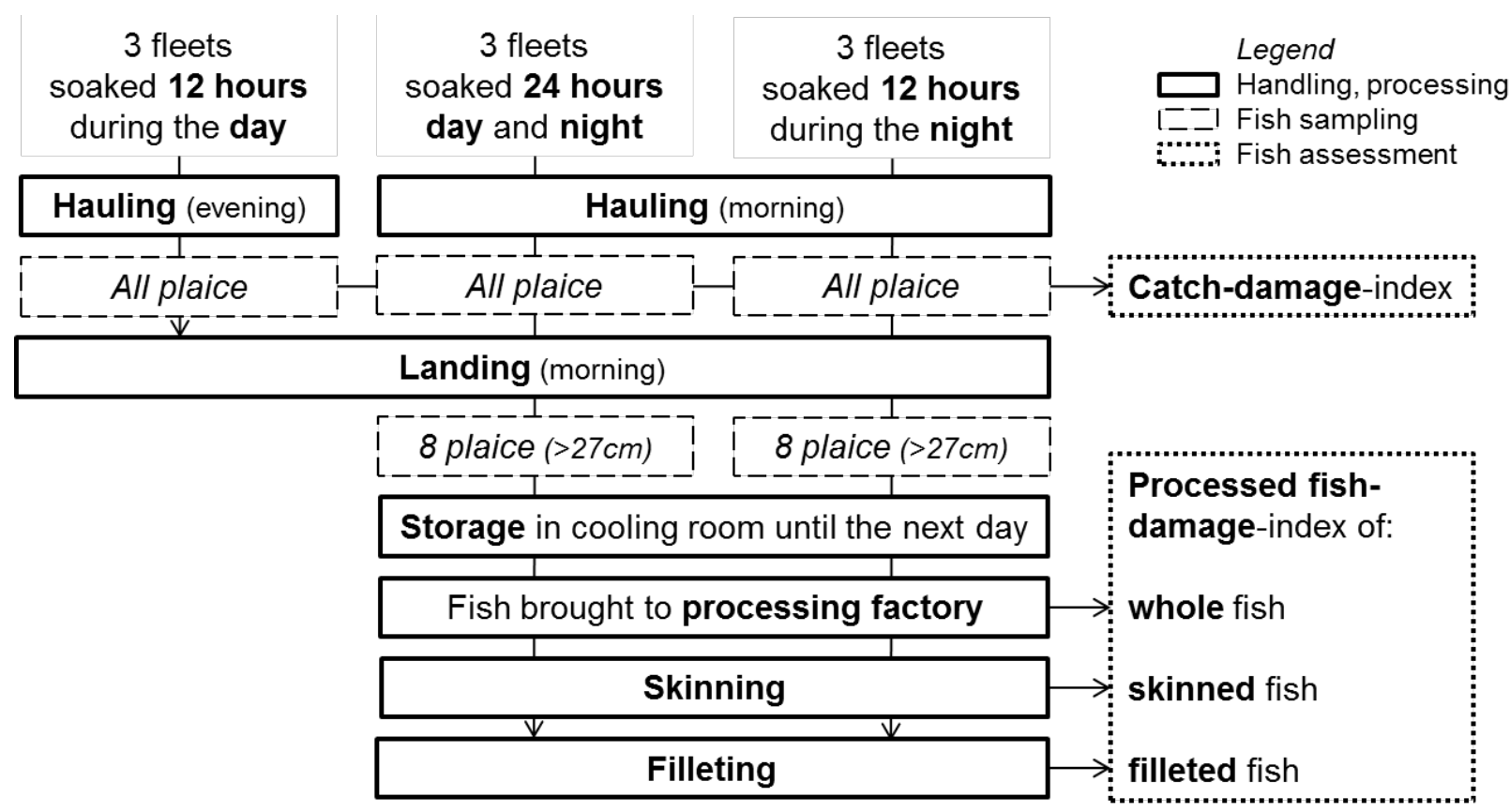


Fig. 2. Examples of ratings of fish onboard the vessel: (a) flawless fish, (b) stripes from gear damage and pressure injuries, (c) stripes from gear damage and descaling, (d) bruises in body part and (e) severe wound, and at the factory: (f) whole fish with no bruises, (g) whole fish with bruises on body part, (h) skinned fish with various degree of bruises, (i) filleted fish with moderate gaping and (j) filleted fish with severe gaping due to injury.
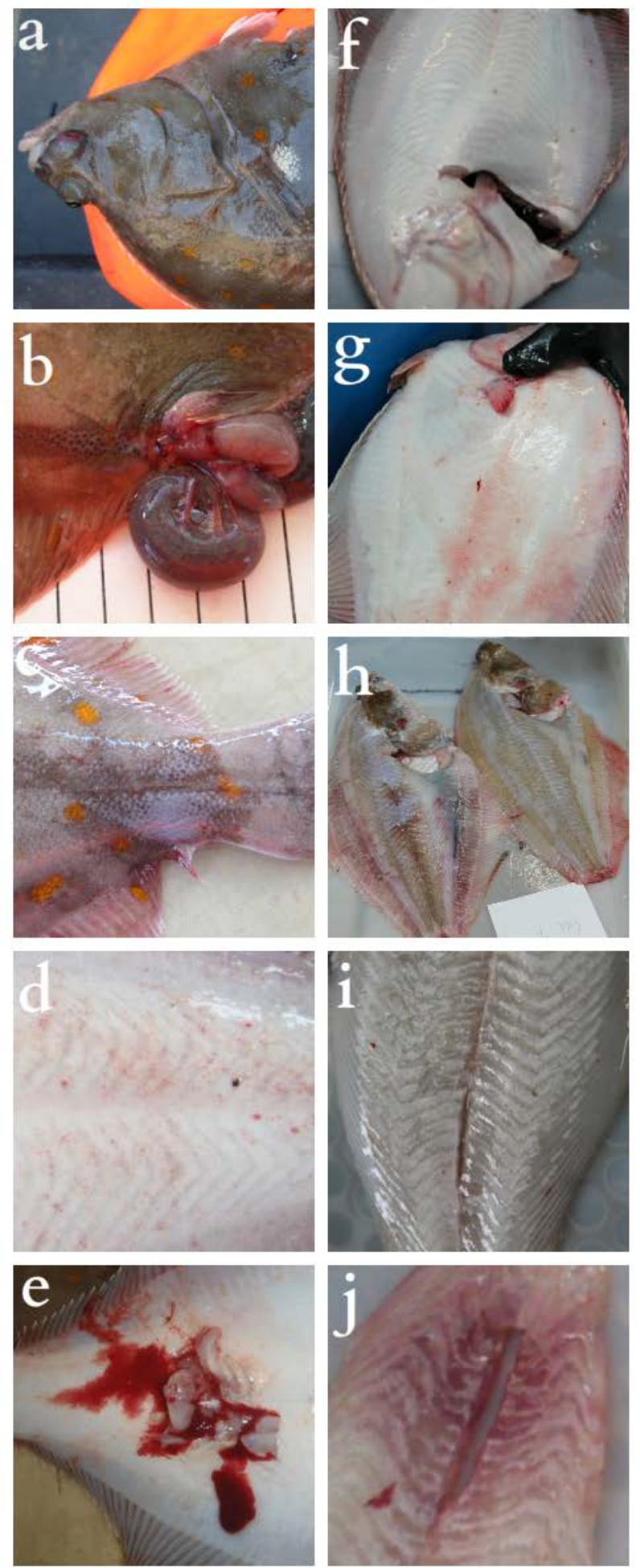
Fig 3. Rating probabilities in the different CDi categories depending on the effect of soak time, for an average-length fish $(31 \mathrm{~cm})$ and average set-effect (50\% percentile set) [left]; the effect of fish length, at $12 \mathrm{~h}$ soak for an average set-effect [middle]; and the set random effect, at $12 \mathrm{~h}$ soak for an average-length fish $(31 \mathrm{~cm})$ [right]. CDi categories range from 0 in light grey for flawless to 9 in black for most severe.
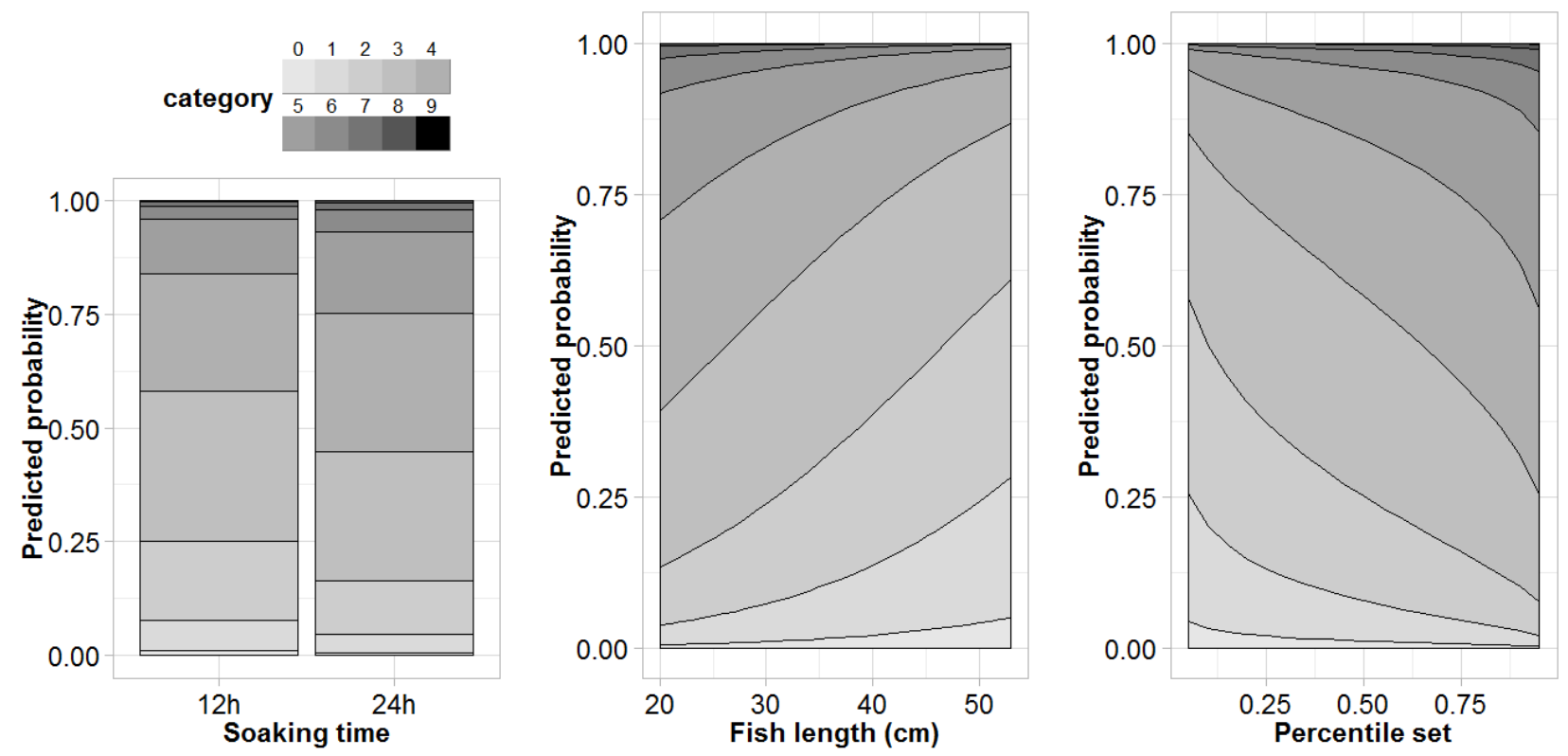

Fig. 4. Rating probabilities in the different Processed fish-damage-index categories depending on the effect of the processing step, for an average fish-effect (50\% percentile fish) [left]; and the fish random effect, for whole fish [right]. Processed fish-damage-index categories range from 0 in light grey for flawless to 4 in black for most severe.
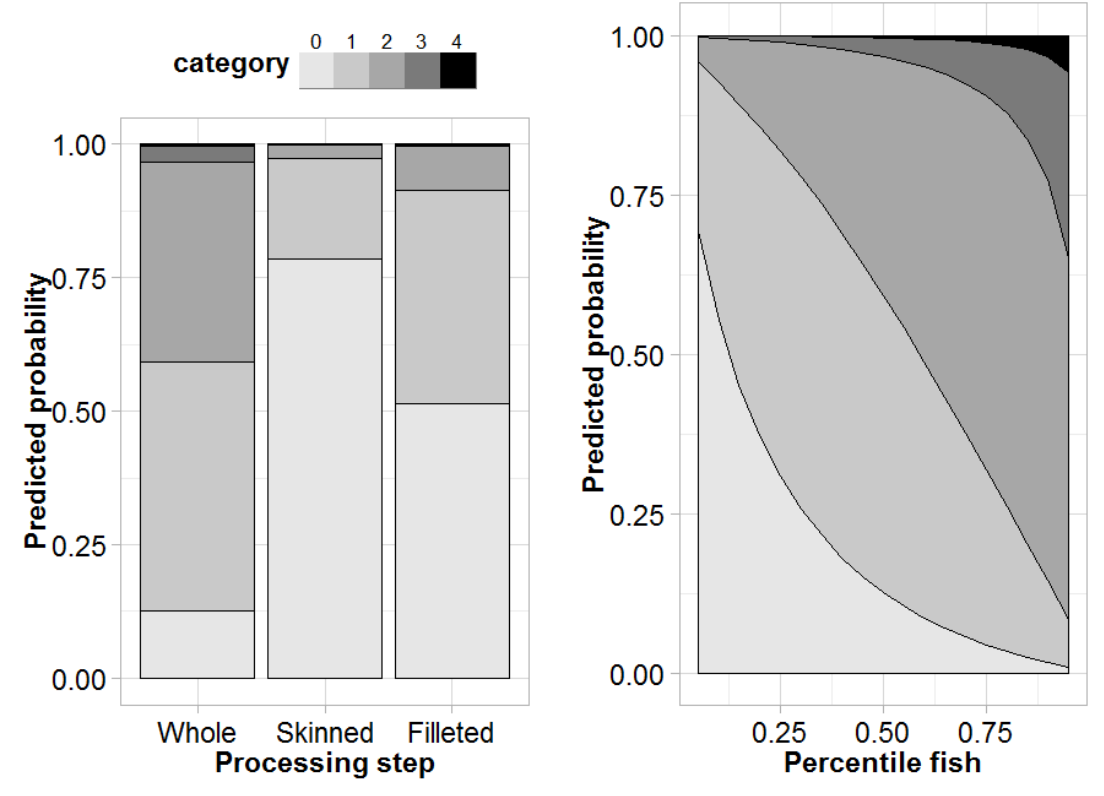
SUPPLEMENTARY DATA: background datasets

Table A.1.

Number of plaice assessed from each set. A set is a combination of the day of data collection (from I to VII), a fleet (A, B or C) and a soaking time (24 hours, 12 hours at day and 12 hours at night).

\begin{tabular}{lllll}
\hline Day & Fleet & 12h day & 12h night & 24h \\
\hline I & A & 13 & 12 & 37 \\
& B & 20 & 16 & 19 \\
& C & 10 & 5 & 34 \\
II & A & 15 & 20 & 33 \\
& B & 8 & 11 & 25 \\
& C & 27 & 13 & 15 \\
III & A & 8 & 4 & 14 \\
& B & 11 & 9 & 25 \\
& C & 9 & 4 & 8 \\
IV & A & 20 & 5 & 23 \\
& B & 9 & 0 & 19 \\
& C & 13 & 13 & 31 \\
V & A & 17 & 21 & 32 \\
& B & 14 & 10 & 16 \\
& C & 6 & 56 & 68 \\
VI & A & 29 & 13 & 11 \\
& B & 57 & 18 & 18 \\
& C & 18 & 24 & 17 \\
VII & A & 40 & 36 & 24 \\
& B & 56 & 46 & 31 \\
& C & 25 & 53 & 24 \\
Total & & 425 & 389 & 524 \\
\hline
\end{tabular}


Table A.2.

Number of individuals and percentage per attributes and rating scores used to calculate the Catchdamage-index for fish assessed onboard the fishing vessel for each soak time.

\begin{tabular}{|c|c|c|c|c|c|c|c|c|c|c|}
\hline \multirow{2}{*}{$\begin{array}{l}\text { Damage } \\
\text { Dead }\end{array}$} & \multirow{2}{*}{$\begin{array}{l}\text { Description } \\
\text { Live }\end{array}$} & \multirow{2}{*}{$\begin{array}{l}\text { Score } \\
0\end{array}$} & \multicolumn{2}{|c|}{ 12h day } & \multicolumn{2}{|c|}{ 12h night } & \multicolumn{2}{|l|}{$12 \mathrm{~h}$} & \multicolumn{2}{|l|}{$24 \mathrm{~h}$} \\
\hline & & & 365 & $86 \%$ & 383 & $99 \%$ & 748 & $92 \%$ & 478 & $91 \%$ \\
\hline & Dead & 2 & 60 & $14 \%$ & 6 & $1.5 \%$ & 66 & $8.1 \%$ & 46 & $8.8 \%$ \\
\hline \multirow[t]{3}{*}{ Gear } & No marks & 0 & 76 & $18 \%$ & 43 & $11 \%$ & 119 & $15 \%$ & 38 & $7.3 \%$ \\
\hline & Stripes, fin damage & 1 & 349 & $82 \%$ & 346 & $89 \%$ & 695 & $85 \%$ & 486 & $93 \%$ \\
\hline & Deep marks, crushing & 2 & 0 & $0.0 \%$ & 0 & $0.0 \%$ & 0 & $0.0 \%$ & 0 & $0.0 \%$ \\
\hline \multirow[t]{3}{*}{ Bruises } & No & 0 & 75 & $18 \%$ & 71 & $18 \%$ & 146 & $18 \%$ & 85 & $16 \%$ \\
\hline & In fin/tail part & 1 & 186 & $44 \%$ & 167 & $43 \%$ & 353 & $43 \%$ & 226 & $43 \%$ \\
\hline & In body part & 2 & 164 & $39 \%$ & 151 & $39 \%$ & 315 & $39 \%$ & 213 & $41 \%$ \\
\hline \multirow[t]{3}{*}{ Skin } & No & 0 & 220 & $52 \%$ & 154 & $40 \%$ & 374 & $46 \%$ & 208 & $40 \%$ \\
\hline & Minor & 1 & 205 & $48 \%$ & 232 & $60 \%$ & 437 & $54 \%$ & 309 & $59 \%$ \\
\hline & Severe, perforated skin & 2 & 0 & $0.0 \%$ & 3 & $0.8 \%$ & 3 & $0.4 \%$ & 7 & $1.3 \%$ \\
\hline \multirow[t]{3}{*}{ Pressure } & No & 0 & 320 & $75 \%$ & 306 & $79 \%$ & 626 & $77 \%$ & 364 & $70 \%$ \\
\hline & Squeezed in fin/tail & 1 & 105 & $25 \%$ & 82 & $21 \%$ & 187 & $23 \%$ & 160 & $31 \%$ \\
\hline & In body part & 2 & 0 & $0.0 \%$ & 1 & $0.3 \%$ & 1 & $0.1 \%$ & 0 & $0.0 \%$ \\
\hline \multirow[t]{3}{*}{ Biting } & No & 0 & 309 & $73 \%$ & 223 & $57 \%$ & 532 & $65 \%$ & 297 & $57 \%$ \\
\hline & Damaged fins/tail & 1 & 113 & $27 \%$ & 158 & $41 \%$ & 271 & $33 \%$ & 218 & $42 \%$ \\
\hline & Deep wounds/bite marks & 2 & 3 & $0.7 \%$ & 8 & $2.1 \%$ & 11 & $1.4 \%$ & 9 & $1.7 \%$ \\
\hline
\end{tabular}


Table A.3.

Number of individuals and percentage per attributes and rating scores used to calculate the Catchdamage-index for fish assessed onboard the fishing vessel for three fish length classes (small: 2029cm, medium: $30-39 \mathrm{~cm}$ and large: $40-53 \mathrm{~cm}$ ).

\begin{tabular}{lllllllll}
\hline Damage & Description & Score & \multicolumn{2}{l}{ Small } & \multicolumn{2}{l}{ Medium } \\
\hline Dead & Live & 0 & 487 & $90 \%$ & 689 & $93 \%$ & 50 & $91 \%$ \\
& Dead & 2 & 53 & $9.8 \%$ & 54 & $7.3 \%$ & 5 & $9.1 \%$ \\
Gear & No marks & 0 & 57 & $11 \%$ & 93 & $13 \%$ & 7 & $13 \%$ \\
& Stripes, fin damage & 1 & 483 & $89 \%$ & 650 & $88 \%$ & 48 & $87 \%$ \\
& Deep marks, crushing & 2 & 0 & $0.0 \%$ & 0 & $0.0 \%$ & 0 & $0.0 \%$ \\
\multirow{5}{*}{ Bruises } & No & 0 & 76 & $14 \%$ & 143 & $19 \%$ & 12 & $22 \%$ \\
& In fin/tail part & 1 & 282 & $52 \%$ & 282 & $38 \%$ & 15 & $27 \%$ \\
& In body part & 2 & 182 & $34 \%$ & 318 & $43 \%$ & 28 & $51 \%$ \\
\multirow{5}{*}{ Skin } & No & 0 & 134 & $25 \%$ & 410 & $55 \%$ & 38 & $69 \%$ \\
& Minor & 1 & 399 & $74 \%$ & 330 & $44 \%$ & 17 & $31 \%$ \\
& Severe, perforated skin & 2 & 7 & $1.3 \%$ & 3 & $0.4 \%$ & 0 & $0.0 \%$ \\
\multirow{5}{*}{ Pressure } & No & 0 & 401 & $74 \%$ & 549 & $74 \%$ & 40 & $73 \%$ \\
& Squeezed in fin/tail & 1 & 139 & $26 \%$ & 193 & $26 \%$ & 15 & $27 \%$ \\
& In body part & 2 & 0 & $0.0 \%$ & 1 & $0.1 \%$ & 0 & $0.0 \%$ \\
& No & 0 & 322 & $60 \%$ & 466 & $63 \%$ & 41 & $75 \%$ \\
& No & 1 & 209 & $39 \%$ & 268 & $36 \%$ & 12 & $22 \%$ \\
& Damaged fins/tail & 1 & 9 & $1.7 \%$ & 9 & $1.2 \%$ & 2 & $3.6 \%$ \\
\hline
\end{tabular}

Table A.4.

Number of individuals and percentage per attributes and rating scores used to calculate the Processed fish-damage-index for fish at three different processing steps.

\begin{tabular}{lllllllll}
\hline Attribute & Sescription & Score & \multicolumn{2}{l}{ Whole } & \multicolumn{2}{l}{ Skinned } & \multicolumn{2}{c}{ Filleted } \\
\hline Surface & Glossy, smooth & 0 & 20 & $25 \%$ & 77 & $96 \%$ & 77 & $96 \%$ \\
& Bright, few scale loss/gapings & 1 & 59 & $74 \%$ & 3 & $3.8 \%$ & 2 & $2.5 \%$ \\
& Dull, many scale loss/gapings & 2 & 1 & $1.3 \%$ & 0 & $0.0 \%$ & 1 & $1.3 \%$ \\
\multirow{5}{*}{ Bruises } & & & & & & & & \\
5 & No & 0 & 36 & $45 \%$ & 56 & $70 \%$ & 49 & $61 \%$ \\
& Few & 1 & 44 & $55 \%$ & 22 & $28 \%$ & 29 & $36 \%$ \\
& Many & 2 & 0 & $0.0 \%$ & 2 & $2.5 \%$ & 2 & $2.5 \%$ \\
& Pre-rigor or rigor, normal & 0 & 80 & $100 \%$ & 80 & $100 \%$ & 70 & $88 \%$ \\
& Firm & 1 & 0 & $0.0 \%$ & 0 & $0.0 \%$ & NA & \\
& Soft, jelly & 2 & 0 & $0.0 \%$ & 0 & $0.0 \%$ & 10 & $13 \%$ \\
\hline
\end{tabular}

